ESTUDIOS - $\mathrm{N}^{\circ} 38$-ISSN 0328-185X (Julio-Diciembre 2017) 125-128

\title{
SEMINARA, Luciana, (2015), Montoneros Sabino Navarro, historia de una disidencia. Buenos Aires: Imago Mundi. 157 pp.
}

\author{
Carlos Ignacio Custer ${ }^{1}$
}

El libro, resultado de la investigación doctoral de la autora, aborda la historia de Montoneros Sabino Navarro (SN), una organización políticomilitar surgida en 1972 como escisión de Montoneros. Como sostiene Seminara, su propuesta busca recuperar la singularidad del devenir de dicha organización entendiéndola en relación con el contexto político y social en el cual estuvo inserta, lo que supone dos cuestiones importantes: por un lado, en cierta medida la labor emprendida implica abordar los derroteros de Montoneros a partir de la óptica de quienes en determinado momento esgrimicron críticas hacia su propia organización y terminaron por emprender el camino de la constitución de un nuevo agrupamiento; por otro lado, la reconstrucción del itinerario y de las concepciones sostenidas por la SN permite romper con la imagen simplificadora y centrada en las dos organizaciones armadas revolucionarias emblemáticas de aquellos años (Montoneros y el Partido Revolucionario de los Trabajadores-Ejército Revolucionario del Pueblo [PRT-ERP]) que transmiten los textos referidos a la radicalización política y a la lucha armada en los setenta con una mareada tendencia a soslayar la existencia de expresio- nes más acotadas que imprimicron cierta singularidad a la cultura militante y a la experiencia política que caracterizaron dichos procesos.

En el primer capítulo la autora efectúa una aproximación global a la trayectoria de la SN describiendo con detenimiento el proceso que dio nacimiento a la organización. EI origen de la misma se remonta a un documento autocrítico realizado en la cárcel por unos militantes montoneros que buscaban iniciar un debate interno respecto de la práctica política y militar llevada a cabo por su propia organización desde sus inicios. La negativa de la conducción no impidió que el texto mecanografiado circulara por diversos ámbitos de la militancia y derivó en la expulsión de los militantes que adoptaron los planteos expuestos en el texto que pasó a ser conocido como el «Documento Verde». La crítica a Montoneros manifestada en dicho escrito se centraba en dos pilares fundamentales: el movimentismo y el foquismo. Lo primero residía en considerar al movimiento peronista como revolucionario en su conjunto y a Montoneros como el brazo armado del mismo. Por eso, según sus críticos, Montoneros se concentró en desarrollar la práctica armada sin reparar en que el

\footnotetext{
a Licenciado en Ciencia Política por la Universidad de Buenos Aires. Becario Doctoral del Conscjo Nacional de Investigacioncs Cícntíficas y Técnicas. Contacto:

carlosignaciocuster@gmail.com
} 
movimiento peronista respondía fundamentalmente a los intereses de las burocracias y sectores burgueses en su seno. Esto llevaba a priorizar las tareas militares (foquismo armado) no permitiendo una profundización política que supusiera como práctica concreta el desarrollo de la organización independiente de la clase obrera y del pueblo peronista como condición indispensable para la revolución. Retomando esos planteos, la SN conformada por los militantes expulsados de Montoneros y que tuvo sus núcleos originarios y principales en las ciudades de Córdoba y Rosario (extendiéndose en menor medida también a Buenos Aires y Tucumán), intentó desplegar una política centrada en la auto-organización de la clase obrera y del pueblo peronista valiéndose del marxismo como una ciencia histórica.

En el segundo capítulo la autora analiza las políticas dadas por la SN hacia los frentes sindicales. Si bien la SN desplegó su actividad política a nivel estudiantil, barrial y fabril, es en este último ámbito donde concentró sus mayores esfuerzos. A nivel general, la política fabril de la SN conjugaba un férreo enfrentamiento a los sectores patronales y a la burocracia sindical, la negativa a participar en la disputa de las conducciones gremiales con la ortodoxia peronista, al tiempo que buscaba construir la auto-organización de la clase obrera desde la base por medio de los organismos que esta generaba en el propio ámbito del trabajo (comisiones internas o cuerpos de delegados). En esa tarea la SN puso en práctica dos modos de inserción diferentes. En Rosario, la organización estableció contactos personales con distintos «dirigentes natu- rales» del movimiento obrero de la zona y su práctica se orientó a acompañar el proceso de sus luchas, servir como referencia y nexo entre diversas expresiones sindicales, pero sin que esos referentes gremiales pasaran a formar parte de la estructura orgánica de la SN. En Córdoba, en cambio, la SN promovió la estructuración de una organización de masas (Peronismo Descamisado) que reunía a las distintas experiencias barriales y sindicales que se referenciaban en la propia organización, aunque dicha vinculación no era expresada explícitamente. La autora destaca que los diferentes dispositivos desplegados para desarrollar la auto-organización obrera remiten a las especificidades de cada zona, pero también al objetivo de construir las bases para la emergencia de una organización político-militar desde la clase obrera que contuviera a su propia vanguardia, en tanto que la invisibilidad en que se mantenía la $\mathrm{SN}$ en ambas experiencias fabriles expresaba que en ese esquema ella solo se reservaba el rol de ser su embrión.

El tercer capítulo examina el discurso político e ideológico desplegado por la $\mathrm{SN}$ a través de sus publicaciones, primero a través de una columna de la revista Militancia Peronista para la liberación y luego por medio de su propia publicación -Puro Pueblo [PP] -que contó con 6 números editados entre Julio y Septiembre de 1974. En el mismo se observa una apelación constante al «peronismo de las bases» constituido por las comisiones internas y los cuerpos de delegados en lucha contra el «peronismo patronal» encarnado por la burocracia sindical. Frente al pacto social implementado por el gobierno pe- 
ronista, PP llamó a quebrarlo y fomentar desde las bases el control obrero de la producción, diferenciándose de Montoneros que en ese momento promovía su reformulación y el control de su cumplimiento en las empresas por parte de los obreros. La autora destaca que la construcción identitaria de la publicación osciló entre las categorías de pueblo peronista y clase obrera, deslizándose progresivamente hacia la segunda a medida que profundizaba su discurso confrontativo. El objetivo específico de PP fue el de difundir el desarrollo de los frentes de masas donde la SN tenía algún nivel de inserción entrelazando de algún modo lo que estaba desarticulado, siendo que la vincưlación con la organización tampoco fue explicitada por la publicación. El espacio destinado a realzar y difundir estas expresiones de lucha permitía a PP desplegar una estrategia discursiva coincidente con la política de la $\mathrm{SN}$ de fomentar la autoorganización obrera al tiempo que invisibilizaba a la propia organización que se mantenía al modo de una vanguardia en las sombras.

El cuarto capítulo indaga sobre el papel asignado a la lucha armada en la experiencia de la SN. Sin dejar de validar esa práctica como forma de intervención política, los sabinos conformaron un pequeño aparato armado que funcionó con la finalidad de proveer al sostenimiento económico de la organización. A diferencia de otras organizaciones de la época, la $\mathrm{SN}$ no buscó construir un ejército revolucionario, ni propagandizar su estructura por medio de acciones armadas, manteniendo en gran medida desvinculado el aparato armado del resto de la organización. Esta autonomía, sin embargo, no derivó en un traslado de la lógica militar a la construcción política dado que uno de los pilares fundacionales de la $\mathrm{SN}$ era el de revertir la subordinación de la política a las armas que había caracterizado a Montoneros. Esto se evidenció en que la mesa nacional estaba conformada por representantes de los diferentes frentes de masas ocupando la célula armada un claro lugar subordinado, en el hecho de que los sabinos militaban respectivamente en un frente de masa y que la $\mathrm{SN}$ no implementó ningún tipo de rangos ni jerarquías militares en su estructuración interna.

En el quinto capítulo, la autora expone el proceso que llevó a la disolución de la SN en 1975. Al poco de tiempo de haber realizado su primer y único congreso nacional que tuvo como objetivo dotar de cierta formalización a la estructura de la organización y establecer algunas definiciones políticas comunes, la SN se disolvió abruptamente en un contexto político nacional marcado por la intensificación de la violencia y del accionar represivo. Sin embargo, la autora arguye que si bien dicho contexto puede haber jugado en favor de la extinción de la $\mathrm{SN}$, ello no agota las razones que pusieron fin a su existencia, toda vez que esto obedeció a cuestiones internas y fundamentalmente a que el proceso abierto con el regreso de Perón al país estuvo signado por el crecimiento político y organizativo de Montoneros, al tiempo que la escena política pasaba a estar dominada por el enfrentamiento creciente entre la izquierda y la derecha peronista, haciendo más difícil el posicionamiento de los sabinos ante dicha coyuntura. Esto tam- 
